\title{
Why are capitulum morphs associated with other characters in natural populations of Senecio vulgaris (groundsel)?
}

\author{
G. S. OXFORD*, T. J. CRAWFORD \& K. PERNYES \\ Department of Biology, University of York, PO Box 373, York YO1 5YW, U.K.
}

\begin{abstract}
The capitulum polymorphism in Senecio vulgaris (groundsel) has previously been shown to have arisen in Britain following hybridization with the introduced species $S$. squalidus (Oxford ragwort). In natural populations, suites of developmental, morphological, reproductive and electrophoretic characters are often found to be associated with the radiate and non-radiate capitulum morphs. Here we demonstrate that the reasons for these character associations may vary among different populations. In plants from Acomb and Morpeth, there is no evidence of genetic linkage between the capitulum locus and those controlling a range of other characters. It is suggested that the associations between characters in these populations are a result of very low outcrossing rates between the two capitulum morphs so that chance associations present in founder individuals are not dispersed. In a population from York, however, linkage is shown to be present and provides an adequate mechanism to explain most of the character associations. York radiate plants may represent the product of a recent introgressive event involving S. squalidus. On the basis of linear discriminant function scores, in all three populations, both radiate and non-radiate progeny in the $F_{2}$ generation from crosses derived from radiate female parents are shown to be more radiate-like than equivalent progeny derived from the reciprocals with non-radiate female parents. The reason for this bias is not clear.
\end{abstract}

Keywords: capitulum polymorphism, founder effect, groundsel, linkage, Senecio vulgaris.

\section{Introduction}

It is now well established that the capitulum polymorphism in groundsel (Senecio vulgaris L.) has arisen in Britain as a result of interspecific hybridizations with the introduced Oxford ragwort ( $S$. squalidus L.) (Abbott, 1992 and references therein). Subsequent backcrossings of the hybrid plants with $S$. vulgaris var. vulgaris $\mathrm{L}$. have led to introgression of a radiate allele $(R)$ into groundsel populations, and this polymorphism is now widespread. Radiate plants $(R R)$ (S. vulgaris var. hibernicus Syme) possess capitula with an outer ring of long-rayed florets whereas non-radiate plants $(N N)$ have capitula lacking the rayed florets. Heterozygotes $(R N)$ exhibit capitula with short-rayed florets, although the ray length is very variable (Richards, 1975). In natural populations, many workers have observed that a variety of other character differences are associated

${ }^{*}$ Correspondence. with the radiate and non-radiate morphs; heterozygotes are rare in the wild and have generally been ignored in this context (but see Richards, 1975). The characters involved can be reproductive (e.g. seed number per capitulum, number of capitula per plant), developmental (e.g. germination time, growth rates), morphological (e.g. degree of leaf dissection, seed length) or electrophoretic (e.g. allozymes of ester-

ases and aspartate aminotransferase), and the differences between capitulum morphs are not necessarily in the same direction in different populations (Richards, 1975; Oxford \& Andrews, 1977; Kadereit \& Briggs, 1985; Abbott, 1986; Marshall \& Abbott, 1987; Warren, 1987; Abbott et al., 1988, 1992a,b). This association between character sets and capitulum morphs has received little detailed attention, although resolving the mechanism(s) responsible could shed important light on the subsequent fate of introduced genetic material after introgressive episodes.

There are three obvious hypotheses that could 
explain why other characters might be associated with capitulum type within a population of $S$. vulgaris.

1 Suites of characters are associated because of genetic linkage - the portion of chromosome introgressed from $S$. squalidus includes not only the capitulum locus but also loci affecting the other traits. These then cosegregate with the capitulum morphs.

2 The loci controlling the characters are not linked to the capitulum locus and the associations observed are a result of selection favouring combinations of coadapted traits that increase fitness under specific environmental conditions.

3 The loci controlling the traits are not linked and the character sets themselves are not coadapted. The associations are present because there is so little outcrossing between radiate and non-radiate plants that chance differences in character traits established between the morphs during the founding of the population are not dispersed.

These hypotheses have been addressed for each of three populations polymorphic for capitulum morphs by within-population reciprocal crosses between radiate and non-radiate plants under glasshouse conditions. $F_{1}$ heterozygotes were then selfed and the characters associated with the radiate and non-radiate morphs in the parents were tested for cosegregation with capitulum morphs in the $F_{2}$. The results show that different hypotheses are required to account for the character associations found in different populations.

\section{Methods}

Bulked seed were collected from 10 radiate and 10 non-radiate plants from each of three polymorphic groundsel populations: Acomb (National Grid Reference, SE 575 514), Morpeth (NGR, NZ 204 854 ) and York (NGR, SE 605 508). At least 50 plants were raised from each stock and their selfed seed collected and bulked. From these, 15 plants of each morph were grown for each population. One capitulum per plant was selected and on three consecutive days it was rubbed with a random capitulum removed from a plant of the other morph from the same population. This procedure yields a mixture of selfed homozygotes and crossed $F_{1}$ heterozygotes. Seeds were bulked for each reciprocal and samples grown to flowering to identify the $F_{1}$ heterozygotes. In some cases the ray florets of heterozygotes were very short and the capitula of plants derived from non-radiate seed parents were dissected under a low-power microscope to ensure correct identification of genotypes. No heterozygotes were found among 40 progeny of non-radiate seed parents from Morpeth. $F_{1}$ heterozygote plants were allowed to self to produce $F_{2}$ populations segregating for all three genotypes. At the same time as the $\mathrm{F}_{2}$ seeds were sown, 20 seeds from each of the bulked parental samples were also sown. Thus both parents and $F_{2}$ plants were raised concurrently under identical conditions. All non-radiate $F_{2}$ plants were confirmed by microscopic dissection of capitula.

The characters measured on parental and homozygous $F_{2}$ plants are listed in Table 1 and sometimes differed among the three populations. Developmental variables used were time to the appearance of the sixth leaf, the time to flowering of the fourth and fifth capitula, and the time to ripening of the first, second and fifth seed heads, all measured as days from germination. Reproductive characters scored were total seed and proportion of empty to total seed in the first, second and fifth capitula, and number of capitula per plant on the day the fifth capitulum fruited. For morphological characters, seed length (mean of five random seeds) was measured for each harvested capitulum, and finally, the longest leaf was taken on the day either the fourth (Acomb) or fifth (Morpeth, York) capitulum opened, pressed flat for $24 \mathrm{~h}$, photocopied and the area and perimeter of the image estimated using a Joyce-Loebel Magiscan Image Analyser, with GENIAS software, version 3.6. A measure of leaf dissection was calculated as (leaf perimeter) $/ \sqrt{\text { (leaf area) }}$ (Warren, 1987). The developmental traits, and repeat measurements of characters based on different capitula, will obviously be interdependent to varying extents.

For each character, mean values were compared between the two parental morphs using a $t$-test. If the difference was significant, then means for the two morphs in the $F_{2}$ were compared. If this difference was in turn significant, the directions of the differences between the morphs in the $F_{2}$ and in the parents were compared. For each population, linear discriminant function analysis (MINITAB, release 8) was performed on all characters measured in the parents. For each morph a linear discriminant function was obtained (see MINITAB, 1991, Ch. 9, p. 7) and from these a discriminant function for differences between morphs was derived by subtracting the coefficients of the discriminant function for the non-radiate morph from those for the radiate morph, and ignoring the constant terms. This equation was then used to calculate an overall score for each parent and $F_{2}$ plant, thus distilling all variables 
Table 1 Mean character scores and standard errors for parental and $\mathrm{F}_{2}$ radiate $(R R)$ and non-radiate $(N N)$ Senecio vulgaris

\begin{tabular}{|c|c|c|c|c|c|c|c|}
\hline \multirow[b]{2}{*}{ Character $\dagger$} & \multicolumn{2}{|c|}{ Parents } & \multicolumn{2}{|c|}{$\mathrm{F}_{2}$} & \multicolumn{2}{|c|}{$R R$ vs. $N N$} & \multirow[b]{2}{*}{ Direction $\neq$} \\
\hline & $R R$ & $N N$ & $R R$ & $N N$ & Par. & $\mathrm{F}_{2}$ & \\
\hline Acomb & $n=18$ & $n=18$ & $n=32$ & $n=22$ & & & \\
\hline d Days to sixth leaf & $18.72(0.27)$ & $18.94(0.33)$ & $18.44(0.25)$ & $18.50(0.27)$ & NS & & \\
\hline Days to fourth capitulum & $48.18(0.71)$ & $42.44(0.79)$ & $44.87(0.76)$ & $44.41(0.76)$ & $* * *$ & NS & \\
\hline Days to second capitulum seed & $62.89(2.16)$ & $53.61(1.29)$ & $60.63(1.30)$ & $58.29(1.17)$ & $* *$ & NS & \\
\hline Total seed (2) & $52.29(1.39)$ & $41.94(1.53)$ & $47.17(1.66)$ & $48.95(2.20)$ & $* * *$ & NS & \\
\hline Empty/total seed (2) & $0.32(0.06)$ & $0.22(0.03)$ & $0.50(0.04)$ & $0.42(0.03)$ & NS & & \\
\hline m $\quad$ Seed length (2) & $2.56(0.02)$ & $2.16(0.02)$ & $2.41(0.03)$ & $2.39(0.03)$ & $* * *$ & NS & \\
\hline Leaf dissection & $15.91(0.40)$ & $8.91(0.28)$ & $13.08(0.45)$ & $11.92(0.30)$ & $* * *$ & $*$ & + \\
\hline Morpeth & $n=18$ & $n=19$ & $n=14$ & $n=12$ & & & \\
\hline d Days to fifth capitulum & $56.28(0.88)$ & $41.74(0.75)$ & $51.00(1.16)$ & $48.92(1.47)$ & $* * *$ & NS & \\
\hline Days to first capitulum seed & $65.00(0.84)$ & $49.11(0.95)$ & $60.86(0.83)$ & $58.25(1.62)$ & $* * *$ & NS & \\
\hline Days to fifth capitulum seed & $70.06(0.99)$ & $54.79(0.75)$ & $66.21(1.01)$ & $63.58(1.43)$ & $* * *$ & NS & \\
\hline Total seed (5) & $43.06(0.76)$ & $39.29(1.28)$ & $40.00(1.62)$ & $46.00(0.99)$ & $*$ & $* *$ & - \\
\hline Empty/total seed (5) & $0.51(0.05)$ & $0.60(0.04)$ & $0.56(0.06)$ & $0.54(0.05)$ & NS & & \\
\hline $\mathbf{r}$ No. of capitula & $29.72(1.13)$ & $44.53(2.98)$ & $44.86(2.45)$ & $38.83(2.77)$ & $* * *$ & NS & \\
\hline m Seed length (5) & $2.10(0.02)$ & $2.26(0.03)$ & $2.14(0.02)$ & $2.14(0.03)$ & $* * *$ & NS & \\
\hline m Leaf dissection & $11.95(0.20)$ & $8.65(0.19)$ & $10.99(0.28)$ & $10.43(0.32)$ & $* * *$ & NS & \\
\hline York & $n=19$ & $n=19$ & $n=28$ & $n=29$ & & & \\
\hline d Days to fifth capitulum & $54.16(2.13)$ & $64.58(1.23)$ & $55.04(1.17)$ & $65.76(1.41)$ & $* * *$ & $* * *$ & + \\
\hline Days to first capitulum seed & $65.89(2.18)$ & $70.89(1.20)$ & $65.75(1.09)$ & $73.90(1.43)$ & (NS)\# & $\left({ }^{* * *}\right)$ & $(+)$ \\
\hline Days to fifth capitulum seed & $72.21(2.10)$ & $78.11(1.36)$ & $72.43(1.20)$ & $80.38(1.51)$ & $*$ & $* * *$ & + \\
\hline Total seed (1) & $44.11(1.79)$ & $51.11(0.88)$ & $43.93(1.44)$ & $55.17(1.24)$ & $* *$ & $* * *$ & + \\
\hline Total seed (5) & $42.61(1.71)$ & $51.05(1.33)$ & $43.89(1.43)$ & $51.57(1.59)$ & $* * *$ & $* * *$ & + \\
\hline Empty/total seed (1) & $0.60(0.04)$ & $0.28(0.04)$ & $0.62(0.03)$ & $0.41(0.03)$ & $* * *$ & $* * *$ & + \\
\hline Empty/total seed (5) & $0.65(0.04)$ & $0.10(0.02)$ & $0.54(0.04)$ & $0.32(0.04)$ & $* * *$ & $* * *$ & + \\
\hline No. of capitula & $29.37(1.42)$ & $22.00(1.23)$ & $30.11(2.07)$ & $23.76(1.10)$ & $* * *$ & 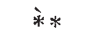 & + \\
\hline Seed length (1) & $2.81(0.03)$ & $2.43(0.02)$ & $2.61(0.05)$ & $2.77(0.05)$ & $* * *$ & * & - \\
\hline m Seed length (5) & $2.98(0.04)$ & $2.25(0.03)$ & $2.66(0.04)$ & $2.68(0.04)$ & $* * *$ & NS & \\
\hline m Leaf dissection & $17.19(0.51)$ & $11.93(0.12)$ & $15.16(0.53)$ & $15.74(0.66)$ & $* * *$ & NS & \\
\hline
\end{tabular}

† Seed length was measured in eyepiece graticule units. The numbers in parentheses indicate the capitulum used. $\mathbf{d}$, $\mathbf{r}$ and $\mathbf{m}$ refer to developmental, reproductive and morphological characters, respectively. $\ddagger$ Indicates whether a significant difference between $\mathrm{F}_{2}$ morphs is in the same $(+)$ or opposite $(-)$ direction to that in the parents. \# and parentheses indicate that the difference between parental means was extremely close to significance $(P=0.055)$ and differences between $\mathrm{F}_{2}$ means were consequently tested. Par., parental. $n$, number of plants.

${ }^{*} P \leq 0.05,{ }^{* *} P \leq 0.01,{ }^{* *} P \leq 0.001$ ( $t$-tests $)$.

into a single number. For each population the mean scores for each of the two parental morphs were averaged to yield mid-parental values. These were subtracted from the scores of the $F_{2}$ plants and the means of these differences for each morph in each population were tested against zero expectation, using $t$-tests.

\section{Results}

The mean character scores for both capitulum morphs in the parental and $F_{2}$ generations are shown in Table 1 for each population. For each character, and for each of the $F_{2}$ radiate and non-radiate morphs, the means of the two reciprocals were compared. Three out of 14 comparisons for Acomb and one out of 22 comparisons for York were significantly different. Each of these cases was examined to confirm that pooling did not mask cosegregation within one of the reciprocal $F_{2}$ progenies. This being the case, results from the reciprocal crosses between parental morphs were combined for Acomb and York. Over all populations, 22 out of 26 tests showed significant differences in means between radiate and non-radiate parents, the majority at $P<0.001$. However, as 
Table 2 Mean discriminant function scores $( \pm 1 \mathrm{SE})$ for radiate $(R R)$ and non-radiate $(N N)$ parental and reciprocal $\mathrm{F}_{2}$ Senecio vulgaris

\begin{tabular}{|c|c|c|c|c|c|c|}
\hline \multirow[b]{2}{*}{ Population } & \multicolumn{2}{|c|}{ Parents } & \multicolumn{2}{|c|}{$\mathrm{F}_{2}(R R) \dagger$} & \multicolumn{2}{|c|}{$\mathrm{F}_{2}(N N) \dagger$} \\
\hline & $R R$ & $N N$ & $R R$ & $N N$ & $R R$ & $N N$ \\
\hline Acomb & $260.1 \pm 2.1$ & $185.8 \pm 2.1$ & $239.0 \pm 6.8$ & $225.6 \pm 3.7$ & $219.4 \pm 4.4$ & $223.8 \pm 5.0$ \\
\hline Morpeth & $118.6 \pm 1.7$ & $54.8 \pm 2.1$ & $94.2 \pm 4.4$ & $95.3 \pm 5.3$ & - & - \\
\hline York & $375.2 \pm 2.6$ & $252.5 \pm 2.8$ & $330.3 \pm 7.4$ & $331.4 \pm 7.4$ & $315.9 \pm 7.1$ & $306.9 \pm 8.0$ \\
\hline
\end{tabular}

$\dagger F_{2}$ reciprocal crosses are designated according to the female parent from which they derive. See text for more details.

mentioned above, not all characters within a population will be independent of one another. Of the characters showing significant differences between parental morphs, only one character is significant in the $\mathrm{F}_{2}$ from each of the Acomb and Morpeth populations. In the Acomb material, the difference in mean leaf dissection between radiate and non-radiate $F_{2}$ is only marginally significant and is in the same direction as in the parents, with the radiate plants having the more dissected leaves. Mean total numbers of seed in the two $F_{2}$ morphs from Morpeth, however, differ in the opposite direction from that shown in the parents. Overall, there is no evidence that characters associated with the capitulum morphs in the Acomb and Morpeth populations cosegregate with their appropriate morphs after passing through the heterozygous state. The York population is very different. Here, 10 out of the 11 characters show significant differences between the parental morphs, and the eleventh character, time to first seed, is only just nonsignificant. Of the 10 characters, eight show significant differences between the morphs in the $F_{2}$. Time to first seed also shows a highly significant difference between $F_{2}$ morphs. If this character is included, eight out of the nine significant $F_{2}$ characters show differences between the morphs in the same direction as in the parents.

Two characters show a significant reversal in the sign of the morph difference in the $F_{2}$ compared with that in the parents; total seed (fifth capitulum) at Morpeth and seed length (first capitulum) at York (Table 1). There is no obvious explanation for these results. Note that the characters concerned differ between populations. In addition, even though the effect is apparent for both of the York reciprocal $F_{2}$ s, the effect is not shown by the fifth capitulum in either reciprocal cross.

Means and standard errors of the discriminant function scores are given in Table 2 for the parent plants and for radiate and non-radiate $F_{2}$ plants
Table 3 Discriminant function mid-parental values and deviations from them for radiate $(R R)$ and non-radiate $(N N) \mathrm{F}_{2}$ Senecio vulgaris

\begin{tabular}{|c|c|c|c|c|c|}
\hline \multirow[b]{3}{*}{ Population } & \multirow{3}{*}{$\begin{array}{l}\text { Mid-parent } \\
\text { value }\end{array}$} & \multicolumn{4}{|c|}{$\begin{array}{c}\text { Deviation from mid-parent } \\
\text { value }\end{array}$} \\
\hline & & \multicolumn{2}{|c|}{$\mathrm{F}_{2}(R R) \dagger$} & \multicolumn{2}{|c|}{$\mathrm{F}_{2}(N N) \dagger$} \\
\hline & & $R R$ & $N N$ & $R R$ & $N N$ \\
\hline Acomb & 222.9 & $+16.1^{*}$ & +2.7 & -3.5 & +0.9 \\
\hline Morpeth & 86.7 & +7.5 & +8.6 & - & - \\
\hline York & 313.8 & $+16.5^{*}$ & $+17.6^{*}$ & +2.1 & -6.9 \\
\hline
\end{tabular}

$\dagger \mathrm{F}_{2}$ reciprocal crosses are designated according to the female parent from which they derive. + , deviation in the $\mathrm{F}_{2}$ is in the direction of the radiate parent; -, deviation is in the direction of the non-radiate parent. See text for more details.

${ }^{*} P<0.05$ ( $t$-test) .

from reciprocal crosses. Table 3 shows the mid-parental values for these mean scores and the deviations from these values of the two morph means in the $\mathrm{F}_{2} \mathrm{~s}$ derived from each parental reciprocal cross. When the original seed parent was non-radiate, deviations of the $\mathrm{F}_{2}$ morph means from the mid-parent values are small and random in direction (two higher, two lower). When the original seed parent was radiate, however, both radiate and non-radiate $\mathrm{F}_{2}$ means deviate in the direction of the radiate parent in all six cases (two-tailed binomial probability $=0.031$ ). In three of these comparisons, individual plant deviations are on average also significantly different from zero ( $t$-test, $P<0.05$ in all cases).

\section{Discussion}

The very strong associations between capitulum morphs and a variety of reproductive, developmental 
and morphological characters in the parental populations from the three different sites investigated here exemplify the widespread nature of this phenomenon. In the York population there is clear evidence for the cosegregation of the locus determining the capitulum morph and loci influencing the other characters, implying that they are physically linked on the same chromosome segment. It seems likely that the linkage group containing the radiate allele, and those for associated character traits, has been established in this York groundsel population after a hybridization event with $S$. squalidus, and has survived intact. In the Acomb and Morpeth populations there is no evidence for the cosegregation in the $F_{2}$ of characters associated with the capitulum morphs in the parental generation. This indicates that, in these populations at least, the capitulum locus is not linked to those determining the other characters. The difference, in this respect, between York and the other two populations may originate from the polymorphisms being produced by different introgressive events. Hybridization and subsequent introgression of $S$. squalidus genes into $S$. vulgaris populations may have occurred on several occasions (Crisp, 1972 cited by Abbott et al., 1992a) and it would be surprising if the amount and disposition of $S$. squalidus genetic material introgressed on each occasion were the same. In some cases just one linkage group containing the radiate allele may have been transferred whereas in other cases additional groups may have established in the $S$. vulgaris genome. (This would suggest the unrecognized existence of monomorphic non-radiate populations of $S$. vulgaris carrying genetic material introgressed from $S$. squalidus that failed to include the capitulum locus.) An alternative explanation is that normally a single linkage group containing the capitulum locus is transferred from $S$. squalidus and that, over time, chromosomal rearrangements disperse this material more widely through the genome. On this hypothesis, the capitulum polymorphism in our York population is of relatively recent origin, a conclusion that concurs with evidence from an electrophoretic analysis of esterase isozyme distributions (Irwin \& Abbot, 1992). Their radiate plants were sampled from two sites in York $\approx 1 \mathrm{~km}$ north and $\approx 1 \mathrm{~km}$ west of our York population; our Acomb population was less than $2 \mathrm{~km}$ further west from the latter of these two sites. In either case, the wide range of characters that cosegregates with the capitulum morph in York suggests that the linkage group involved must be relatively large.

Whereas it appears that linkage is a sufficient explanation for the strong associations between the capitulum morphs and most of the other characters in the York population, in the Acomb and Morpeth populations this hypothesis can be eliminated. The second hypothesis, selection for coadapted character combinations, cannot be rejected entirely but it seems unlikely. Many populations of groundsel reported in the literature were growing in similar, urban environments yet the characters associated with the radiate and non-radiate morphs are often very different (e.g. Oxford \& Andrews, 1977; Marshall \& Abbott, 1987; Warren, 1987). The sheer range of characters involved also makes it difficult to believe that strong interactions exist between each of these and the capitulum morphs such that the fitnesses of the latter are increased. Abbott et al. (1992a), however, have argued that selection is probably responsible for the observed association between allozymes at the aspartate aminotransferase (Aat) locus and the unlinked capitulum locus. Selective interaction between capitulum morphs and one other character would be sufficient provided that further trait differences were linked to that character. If true, the implication is that these other characters are less subject to selection than is the interaction. The hypothesis that these associations result from low levels of outcrossing between the capitulum morphs is much more attractive. Although relatively high frequencies of intermorph outcrossing (up to 35 per cent) have been reported in some natural populations (Marshall \& Abbott, 1984), the proportion of heterozygous plants in the wild is nonetheless very low (e.g. Hull, 1974; Oxford \& Andrews, 1977; Marshall \& Abbott, 1982, 1984). It is possible that the high levels of outcrossing observed in seed taken from parent plants is not translated into viable individuals capable of reproduction (see also Abbott et al., 1992b). In many populations, therefore, the exchange of genes between morphs may be very small and each acts, in effect, as a semiisolated gene pool. Groundsel is an ephemeral weed species and an early colonizer of open ground. Under these circumstances it is likely that many groundsel populations are founded by a very small number of propagules in which chance associations between capitulum morphs and a variety of other characters will occur. With low levels of gene exchange between capitulum morphs, these associations will become 'fossilized' as the population expands. This hypothesis would predict that characters associated with particular capitulum morphs should not be constant across populations, as is indeed the case.

Finally, the crosses described here produced one totally unexpected outcome. Mean character scores, 
derived from discriminant function analyses, for both radiate and non-radiate $F_{2}$ plants from the non-radiate seed parent were very similar to the mid-parental values. However, the scores for $F_{2}$ plants, both radiate and non-radiate, derived from the radiate seed parent showed a consistent bias towards the radiate parent. This cannot be a simple maternal effect because $F_{2}$ plants are two generations removed from the parental stocks. It appears that some factor, originating in the radiate parent and inherited through the female line, influences the expression of a number of character loci towards that of the radiate parent. The effect was apparent in all three populations studied. If an equivalent factor exists in non-radiates it seems to be ineffective. What this factor might be is not obvious, but it may be associated with either the mitochondrial or chloroplast genomes. This phenomenon clearly demands further investigation.

\section{Acknowledgements}

We would like to thank Richard Abbott and John Warren for comments on the manuscript, John Byrne for helpful statistical discussions and the late Keith Partridge for horticultural assistance.

\section{References}

ABвOTT, R. J. 1986. Life history variation associated with the polymorphism for capitulum type and outcrossing rate in Senecio vulgaris L. Heredity, 56, 381-391.

Аввотт, R. J. 1992. Plant invasions, interspecific hybridization and the evolution of new plant taxa. Trends Ecol. Evol., 7, 401-405.

ABBOTT, R. J., HORRILL, J. C. AND NOBLE, G. D. G. 1988. Germination behaviour of the radiate and non-radiate morphs of groundsel, Senecio vulgaris L. Heredity, 60, $15-20$.

ABBOTT, R. J., ASHTON, P. A. AND FORBES, D. G. 1992 a.
Introgressive origin of the radiate groundsel, Senecio vulgaris L. var. hibernicus Syme: Aat-3 evidence. Heredity, 68, 425-435.

ABBOTT, R. J., IRWIN, J. A. AND ASHTON, P. A. $1992 \mathrm{~b}$. Genetic diversity for esterases in the recently evolved stabilized introgressant, Senecio vulgaris L. var. hibernicus Syme, and its parental taxa S. vulgaris L. var. vulgaris, L. and S. squalidus L. Heredity, 68, 547-556.

CRISP, P. C. 1972. Cytotaxonomic Studies in the Section Annui of Senecio. Ph.D. Thesis, University of London.

HULL, P. 1974. Self-fertilisation and the distribution of the radiate form of Senecio vulgaris L. in Central Scotland. Watsonia, 10, 69-75.

IRWIN, J. A. AND ABBOTT, R. J. 1992. Morphometric and isozyme evidence for the hybrid origin of a new tetraploid radiate groundsel in York, England. Heredity, 69, 431-439.

KADEREIT, J. W. AND BRIGGS, D. 1985. Speed of development of radiate and non-radiate plants of Senecio vulgaris $\mathrm{L}$. from habitats subject to different degrees of weeding pressure. New Phytol., 99, 155-169.

MARShAlL, D. F. AND ABBotT, R. J. 1982. Polymorphism for outcrossing frequency at the ray floret locus in Senecio vulgaris L. I. Evidence. Heredity, 48, 227-235.

MARSHALL, D. F. AND ABBOTT, R. J. 1984. Polymorphism for outcrossing frequency at the ray floret locus in Senecio vulgaris L. II. Confirmation. Heredity, 52, 331-336.

MARSHALL, D.F. AND ABBOTT, R. J. 1987. Morph differences in seed output and the maintenance of the polymorphism for capitulum type and outcrossing rate in Senecio vulgaris L. Trans. Bot. Soc. Edinb., 45, 107-119. MINITAB, 1991. mINITAB Reference Manual. Release 8 (PC version). Minitab Inc., State College, PA.

OXFORD, G.S. AND ANDREWS, T. 1977. Variation in characters affecting fitness between radiate and non-radiate morphs in natural populations of groundsel (Senecio vulgaris L.). Heredity, 38, 367-371.

RICHARDS, A. J. 1975 . The inheritance and behaviour of the rayed gene complex in Senecio vulgaris. Heredity, 34, 95-104.

warren, J. M. 1987. The Origin and Maintenance of the Capitulum Polymorphism in Senecio vulgaris $L$. (groundsel). D.Phil. Thesis, University of York. 